\title{
ISOLATION AND IDENTIFICATION OF SOIL MYCOFLORA IN AGRICULTURAL FIELD OF SADAK ARJUNI OF GONDIA DISTRICT (MS)
}

\author{
Sunil M. Akare \\ Department of Botany, Manoharbhai Patel College, SadakArjuni, Dist. Gondia (MS) - 441807 \\ E-mail: akaresunil@gmail.com
}

\section{ABSTRACT:}

Soil samples were collected from different locations of Sadak Arjuni of Gondia District during the months of February 2014 to January 2015 in three intervals. The samples collected in two zones viz. rhizoplane and rhizosphere. The collected samples were inoculated in Potato Dextrose Agar (PDA) and CzapekDox Agar (CDA) medium supplemented by antibiotics such as penicillin and Streptomycin by using Serial dilution method and soil plate method. A total of 230 colonies were isolated. About 19 species belonging to 7 genera of fungi were isolated and identified while 21 strains were unidentified. Identification and characterization of the soil mycoflora were made with the help of authentic manuals of soil fungi. Maximum number of fungal colonies belonged to Ascomycotina and Deutero mycotina (191) and few to zygomycotina (18). Among the isolates Aspergillus flavus, A. fumigatus, A. nidulans, A.niger, A.terreus, Fusarium oxysporum, Penicillium chrysogenum, Rhizopusstolonifer and Trichoderma viridae were predominant. The percentile contribution of the mycoflora was graphically and statistically analyzed.

Keywords: Microfungi, Culture Media, Isolation, Fungal Diversity.

\section{INTRODUCTION:}

Soils are extremely complex structures with many constituents playing diverse functions mainly due to the activity of soil organisms (Chiang and Soudi, 1994). Soil microflora plays a essential role in evaluation of soil conditions and in stimulating plant growth (Kiran et al.,1999). Microorganisms are helpful in increasing the soil fertility and plant development as they are included in several biochemical transformation and mineralization activities in soils. Method of cultivation and crop management practices found to have greater influence on the activity of soil microflora (Mc.Gill et al., 1980). Continuous use of chemical fertilizers over a long period affecting soil microflora and thereby indirectly affect biological properties of soil leading to soil degradation (Manickam et al., 1972).

There is a massive microbial flora present in the earth and they are found in all types of soils (Mukherji et al., 2006). These microbes may interact with the plants resulting sometimes in useful effect and other times in harmful consequences. Fungi are an important component of the soil microflora and are present in the form of mycelium, rhizomorphs or as spores. They play important role in soils and plant nutrition. Saprophytic fungi are able to live on dead and decaying organic matter. They secrete a varied number of enzymes that attacks effectively any organic material and converting it into simple soluble forms, which are readily available to higher plants. Due the degradative activities fungi play important role in recycling organic waste in environment. Unfortunately their degradative ability also results in the undesirable growth of fungi that destroy useful materials (Aina et al., 2011). Fungi grow on diverse habitats in nature and are cosmopolitan in distribution requiring several specific elements for growth and reproduction. In laboratory, these are isolated on specific culture medium for cultivation, preservation, microscopical examinations and biochemical and physiological characterization (Aina et al., 2011).

The species richness of a fungal community and relative abundance of individual species have been considered as measures of functional activities of the group in the particular habitat (Kjoller and Struwe, 1982). Fungi, bacteria and actinomycetes colonize diverse habitats and substrates and play substantial role in plant health and productivity besides producing diseases. The role of fungi in the soil is an extremely complex one and is fundamental to the soil ecosystem.

\section{Rhizosphere}

The rhizosphere is a micro-ecological zone in direct closeness of plant roots. It is functionally defined as the particulate matter and microorganisms that adhere to roots after being moderately shaken in water. The theoretical extent of the rhizosphere is dependent on the zone of influence of the plant roots and associated microorganisms. The rhizosphere is a metabolically busier, faster moving, more competitive environment than the surrounding soil. 


\section{Rhizoplane}

The rhizoplane is the region around the root epidermis and outer cortex where soil particles, bacterial and fungal hyphae adhere. The functional definition is that after the roots have been shaken rapidly in water the remaining microorganisms and soil particles left are considered as belonging to the region of rhizoplane.

There are more numbers of microbes present in the rhizoplane than in the rhizosphere. The diversity of the fungal population is determined by counting the number of colony forming units (CFUs). By spreading the extracted soil microorganisms across agar and counting the number of independent clusters of microorganisms the CFUs were determined. Micro-organisms are abundant where the reliability of the root is compromised. Hence rhizoplane microorganisms tend to be found on older ones rather than younger roots.

\section{STUDY SITE AND LOCATION:}

Sadak Arjuni of Gondia district (MS) located at $21.10^{\circ} \mathrm{N} 80.15^{\circ} \mathrm{E}$. It has an average elevation of 256 metres (843 feet). It is located near the Maharashtra Chhattisgarh border on Mumbai-Kolkata National Highway 6. The temperature ranges from $15-42^{\circ} \mathrm{C}$. Red Sandy soils andLaterite soils are the major soil types existing.

The climates is characterized by a hot summer, well distributed rainfall during the south-west monsoon season and generally dry weather during the rest of the year. Farmers take up first crop of Paddy with monsoon rainfall and a second of Wheat, Gram, Linseed, Sunflower and many more crops with irrigation in Rabbi Season.

\section{METHOD AND MATERIAL:}

\section{Nutrient Medium Used:}

Potato Dextrose Agar (PDA) and CzapekDox Agar (CDA) medium used for isolation of fungi. The $\mathrm{pH}$ of the medium was maintained at 5.5 being optimal for the growth and sporulation in a majority of fungi.

\section{Collection of Soil Samples:}

The soil samples were collected from Six different crop fields from Six different locations of SadakArjuni. The samples were collected between the months of February 2014 to January 2015 in three intervals. Majority of fungi are microscopic and show huge variation in different sites of collection and at different depths. Therefore soils were collected from a depth of $15 \mathrm{~cm}$ and are kept in sterilized Ziploc polyethylene bags. Each sample bag was labeled properly by indicating the site of collection, time, date and place of collection. The collected soil samples along with locations showed in Table: 1 .

\section{Isolation of fungi from the soil samples:}

The soil microfungi were isolated by two methods, Soil Dilution and Soil Plate method on Potato Dextrose Agar and Czapek,sDox Agar media.

\section{Soil Dilution Plate Method (Waksman, 1922):}

$1 \mathrm{gm}$ of soil sample was suspended in $10 \mathrm{ml}$ of double distilled water to make microbial suspensions $\left(10^{-1}\right.$ to $\left.10^{-5}\right)$. Dilution of $10^{-3}, 10^{-4}$ and $10^{-5}$ were used to isolate fungi. $1 \mathrm{ml}$ of microbial suspension of each concentration were added to sterile Petri dishes (triplicate of each dilution) containing $15 \mathrm{ml}$ of sterile Potato Dextrose Agar or Czapek,sDox Agar medium. One percent streptomycin solution was added to the medium before pouring into petriplates for preventing bacterial growth and incubated at $28 \pm 2{ }^{\circ} \mathrm{C}$ in dark. The plates were observed everyday up to 4-7 days. Fungi were easily isolated because they formed surface colonies that were well dispersed (Fig: 2), particularly at higher dilutions.

Soil Plate Method (Warcup, 1950):

Almost $0.005 \mathrm{~g}$ of soil was dispersed on the bottom of a sterile petri dish and molten cooled $\left(40-45^{\circ} \mathrm{C}\right)$ agar medium (PDA) and (CZA) was added, which was then rotated gently to scatter the soil particles in the medium. The Petri dishes were then incubated at $28 \pm 2^{\circ} \mathrm{C}$ in dark for 4-5 days. One isolate of each fungal genus from each soil sample were selected at random for further subculturing and experiments. The subcultures were maintained on Potato Dextrose Agar.

\section{Inoculating Techniques:}

The working benches in the laboratory were thoroughly sterilized by swapped with $70 \%$ alcohol, and also a burning blue flame was allowed to sterilize the surrounding air before the inoculation proper. The conical flasks were corked tightly with cotton wool and the Petri dishes were fully autoclaved (Aina et al., 2011).

\section{Identification of the Soil Fungi:}

Generally identification of the fungal species is based on morphological characteristics of the colony and microscopic examinations (Diba et al., 2007). The colony growth which includes length and width of the colony, the presence or absence of aerial mycelium, the color, wrinkles furrows and any other pigment production were the macro morphological characters evaluated. Although molecular methods continue to improve and become more rapidly available, microscopy and culture remain commonly 
used and essential tools for identification of fungal species (Diba et al., 2007). The fungi were identified with the help of standard procedure and relevant literature (Gilman, 2001; Nagamani et al., 2006).

\section{Staining Technique for Fungi:}

Inoculating needles were flamed over the burning Bunsen burner. Then using the needle, a small portion of the growth on the culture plate was transferred into the drop of lacto phenol in cotton blue on the slide. The specimen was teased carefully using inoculating wire loops to avoid squashing and over-crowding of the mycelium (Aina et al., 2011). The specimen is observed under the microscope for microscopic identification (Fig: 4).

\section{Statistical Analysis:}

Population density expressed in terms of Colony Forming Unit (CFU) per gram of soil with dilution factors. The CFU and Percent Contribution of each isolate was calculated by -
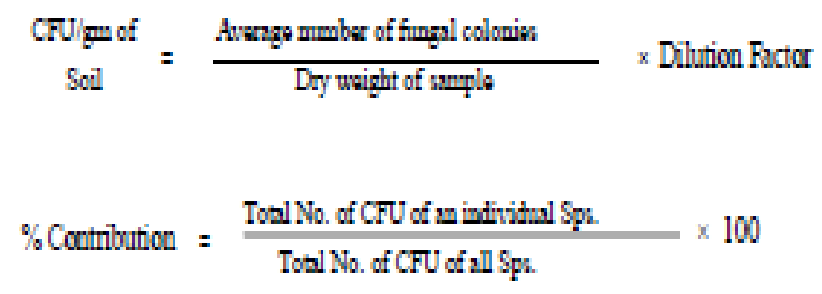

\section{RESULT AND DISCUSSION:}

Soil microorganisms act as vital determinants of plant community variety and productivity (Wardle et al., 2004). The environmental factors such as the soil $\mathrm{pH}$, moisture, temperature, organic carbon and nitrogen play an important role in the distribution of mycoflora (Gaddeyya et al., 2012). These are the main factors affecting the fungal population and diversity. The soil mycoflora in six different rice fields viz., Sadak Arjuni, Wadegaon, Kohmara, Sawangi, Saundad and Tidka were observed. Soil Dilution Plate and Soil Plate methods were used for the isolation of fungi during the present investigation.

During a period of 12 months the total number of fungal colonies isolated on Petri plates containing PDA medium were 229. As stated earlier Soil dilution plate and Soil plate method were employed for the isolation of fungi during the present investigation. A greater number of species and colonies were isolated on soil plates than on dilution plates and further the total number of species isolated decreased with increased dilutions of the samples. The purification of the culture (Fig: 3) was done either by single spore isolation or by culturing of the hyphal tips and was transferred to fresh agar slants of CDA medium. Most of the fungal forms which sporulate heavily were abundant on dilution plates.

Fungi act as major decomposers of dead organic matter and contribute significantly in recycling of nutrients in natural and modified ecosystems (Gadd, 2004). Altogether six soil samples from six different locations were examined for fungal diversity. The study resulted the presence of 19 species of fungi were identified and characterized from PDA plates (Table: 2). the maximum fungal species belonged to Ascomycotina and Deuteromycotina (191 colonies) and Zygomycotina (18 colonies) and 21 colonies were left unknown on the plates containing PDA medium (Table: 2)

PDA medium is the most frequently used culture media and was stated to be the best media for mycelia growth by several workers worked with it earlier (Maheshwari et al., 1999; Saha et al., 2008), due to its simple formulation and potential to support wide range of fungal growth. CDA medium preferred for pure culture to minimize the contamination of Rhizophusstolonifer. Characterization of the isolates up to genus level and to the species level was made based on the macromorphological (Colony characters) and micromorphological characters by using authentic manuals of soil fungi.

Our findings are in accordance with the results of Noor Zaman et al., (2012) as the microbial analysis of different samples in rainfed areas of Punjab, Pakisthan. They isolated genera like Aspergillus, Alternaria, Curvularia, Fusarium, Penicillium and Rhizopus. Similar genera were isolated during our investigation. These findings were similar to those isolated by Rasheed et al., (2004). Aspergillus species particularly like $A$. flavus and $A$. niger, Penicillium and Rhizopus were isolated only from the soil where as Alternaria alternata, Curvularia lunata and Fusarium species were obtained from both soil and plant parts. Hence it is considered that isolation of soil samples yielded more fungal species than from plants (Noor Zaman et al., 2012).

In our investigation among the obtained fungal isolates the genera Aspergillus, Fusarium, Rhizopus and Penicillium were dominant on media used (Tables: 2). The most common isolates among them viz., A. candidus, A. flavus, A. fumigatus, $A$. granulosus, A. nidulans, A. niger, A. ochrasius, A. terreus, Curvularia clavata, C. lunata, C. lunata, 
Fusarium oxysporium, F. solani, Penicillium chrysogenum, P. digitatum, Rhizopus stolonifer, $R$. oryzae, Trichoderma hamatum, T.viride were isolated and characterized.

The percent contribution of different soil mycoflora of all the six Rice fields was evaluated. The fungi were mostly observed in the months of June to October as it has been reported that the diversity of fungal population occurred during the monsoon season where the soil moisture was significantly high (Bissett \& Parkinson, 1979; Deka \& Mishra, 1984).

Isolation of fungal species from soil samples by repeated screening and plating on starch agar medium by Ratnasri et al., 2014 yielded Aspergillus fumigatus and $A$. niger along with other fungal species. Fusarium solani was isolated from the soils of infected fields and showed 100\% frequency (Javed et al., 2008). Recent study on Soil Microflora in National Parks in Gujarat yielded fungal species like Aspergillus niger and Fusarium species (Megha et al., 2015). The conservation of diversity of mycoflora in agricultural fields becomes very essential for the development of sustainable agriculture (Gaddeyya et al., 2012). Natural and anthropogenic disturbances can alter the species composition or may have negative effect on species diversity of the decomposer fungi (Dong et al., 2004). These changes may directly or indirectly affect the vital functions of the soil such as decomposition and mineralization and may result in disturbances. Graphical representation of percent contribution of fungal species diversity in various paddy fields on the media PDA is represented in (Graph:1).

The studies on fungal diversity and percentile contribution and periodic occurrence of soil mycoflora are useful for farmers, agronomists, researchers and microbiologists for future activities in the view of conservation of soil ecosystem, conservation of soil microbial diversity and sustainable agriculture (Gaddeyya et al., 2012).

\section{CONCLUSION}

In the present study the soil sample of six different paddy fields of viz; Sadak Arjuni, Wadegaon, Kohmara, Sawangi, Saundad and Tidka studied for detecting the fungal diversity. The greater fungal population was observed mostly in the monsoon season as the soil moisture was high. Among the isolates Aspergillus, Fusarium, Penicillium, Rhizopus and Trichoderma were dominant in all agricultural fields of all areas mentioned due to high sporulation and production of bacterial antibiotics from the
Penicillium species and production of different types of toxins from the Aspergillus species may prevent the growth of other fungal species. This study is an effort to understand the soil microbial diversity in the agricultural fields of Sadak Arjuni as soil microflora not only plays an important role in decomposition and contribute to biogeochemical cycling but also are responsible for the prevalence of diseases in the crop fields.

\section{REFERANCE :}

Aina VO, Adewuni AAJ, HauwaHaruna and AminaZaraki. Isolation and identification of fungi associated with the deterioration of painted wall surfaces within Kaduna polytechnic. Asian Journal of Medical Sciences, 2011; 3 (6): 250-253.

Bissett $\mathrm{J}$ and Parkinson D. Functional relationship between soil fungi and environmental in alpine tundra. Can. J .Bot., 1979; 57: 1642-59.

Chiang, CN. andSoudi, B., Biologie du sol et cycles biogéochimiques. In: El Hassani TA. andPersoon E (Eds), AgronomieModerne, Bases physiologiques et agronomiques de la production végétale, 1994, 85-118 pp.

Deka HK and Mishra RR. Distribution of soil microflora in jhum fallows in north-east india. ActaBotanicaIndica, 1984; 12 (2): 180-184.

Diba K, kordacheh P, Mirhendi SM, Rezaie S, Mahmoudi M. Identification of Asergillus species using morphological characteristics. Pal.J.Med.sci., 2007; 23 (6): 867-872.

Dong AR, Lv GZ, Wu QY, Song RQ, Song FQ. Diversity of soil fungi in Liangshui Natural Reserve, Xiaoxing'anling forest region, J. Northeast forestry university., 2004; 32(1): 810.

Gadd GM. Mycotransformation of organic and inorganic substrates Mycologist, 2004; 18 (2): 60-70.

Gaddeyya G, Shiny Niharika P, Bharathi P and Ratna Kumar PK. Isolation and Identification of soil mycoflora in different crop fields at 
salurmandal, Adv. Appl. Sci. Res, 2012; 3 (4): 2020-2026.

Gilman JC. A Manual of soil fungi, 2nd Indian Edition, Biotech Books, Delhi, 2001.

Javed MS, Harif M, Niaz M, Ali I. Impact ofstorage period and temperature on the pathogenic behaviour of Fusarium solani on cotton (Gossypiumhirsutum L.) seeds. 2008. Mycopath. 6 (1-2): 7-11.

Kiran Singh, JaishreeBorana and SobhaSrivastava, VA., Journal of Soil Biology and Ecology.,1999, $19: 11-14$.

Kjoller A, Struwe S. Microfungi in Ecosystems.,fungal occurrence and activity in litter and soil,Oikos., 1982; 39 (3): 389-422.

Maheshwari SK, Singh DV, Sahu AK. Effect of several nutrient media, $\mathrm{pH}$ and carbon sources on growth and sporulation of Alternariaalternata, J. Mycopathol.Res., 1999; 37 (1): 21-23.

Manickam, T.S And Venkataraman,C.R., Madras Agricultural Journal., 1972 , 59:508-512.

Mc.Gill,W.B., Cannon, K.R., Robertson, J.A and Cook, F.D., Canadian Journal of Soil Science., 1980, 66: 1-19.

MeghaBhutt, sejalpatel, Puja Prajapti, Jasral YT.Isolation and Identification of Soil Microflora of National parks of Gujarat, India. Int.J.Curr.Microbiol.App.Sci.2015; 4(3): 421 429.

Mukerji KG, Manoharachary $\mathrm{C}$ and Singh J. Microbial Activity in the Rhizosphere., Soil Biology., 2006; 7: 1-6.

Nagamani A, Kumar IK and Manoharachary C. Hand Book of Soil Fungi, I.K. International Publishing House Pvt Ltd, New Delhi, India. 2006.

Noor Zaman, Shakil Ahmed. Survey of Root Rot of Groundnut in Rainfed areas of Punjab, pakisthan.Afr.J.Biotechnol. 2012; 11 (21): 4791-4794.
Rasheed S, Dawar S, Ghaffar A. Location of fungi in groundnut seed. Pak.J.Bot.36 (3): 663- 668.

Ratnasri PV, Lakshmi BKM, Ambika Devi K, Hemalatha KPJ. Isolation, characterization of Aspergillusfumigatus and optimization of cultural conditions for amylase production. International journal of Research in Engineering and Technology.2014; 3 (2): 457463.

Saha A, Mandal P, Dasgupta S, Saha D. Influence of Culture Media and Environmental factors on mycelia growth and sporulation of Lasiodiplodiatheobromae (Pat.)., Griffon and Maubl.J.Environ.Biol., 2008; 29 (3): 407-410.

Waksman SA. A method for counting the number of fungi in the soil. J. Bact., 1922; 7 (3): 339-341.

Warcup JH. The soil plate method for isolation of fungi from soil., Nature., Lond., 1950; 166: 117-118.

Wardle DA, Bardgett RD, Klironomos JN, Setala H, Van der Putten WH, Wall DH. Ecological linkages between above ground and below ground biota. Science 2004, 304 (11): 16291633. 


\begin{tabular}{|c|c|c|}
\hline Sample No. & Agricultural field & Place \\
\hline 1 & Paddy & SadakArjuni \\
\hline 2 & Paddy & Wadegaon \\
\hline 3 & Paddy & Sawmara \\
\hline 4 & Paddy & Saundad \\
\hline 5 & Paddy & Tidka \\
\hline 6 & Paddy & Sand \\
\hline
\end{tabular}

Table 1: Agricultural soil samples collected from different places in SadakArjuni Tehsil

\begin{tabular}{|c|c|c|c|c|c|c|c|c|c|c|c|c|c|c|c|c|c|c|c|c|c|c|}
\hline \multirow{3}{*}{ Sr. No. } & \multirow{3}{*}{ Rice Fields } & \multirow{3}{*}{$\begin{array}{c}\text { Total No. } \\
\text { of } \\
\text { Colonies }\end{array} \mid$} & \multicolumn{20}{|c|}{ Average Number of Individual Colonies } \\
\hline & & & \multicolumn{8}{|c|}{ Aspergillus } & \multicolumn{2}{|c|}{ Curvularia } & \multicolumn{2}{|c|}{ Fusarium } & \multicolumn{2}{|c|}{ Penicillium } & \multirow{2}{*}{\begin{tabular}{|c|} 
Phoma \\
Psp
\end{tabular}} & \multicolumn{4}{|c|}{\begin{tabular}{l|l|} 
Rhizopus & Trichoderma \\
\end{tabular}} & \multirow{2}{*}{ Unknown } \\
\hline & & & Aca & Afl & Afu & Agr & Anid & Ani & Aoc & Ate & $\mathrm{Ccl}$ & $\mathrm{Clu}$ & Fo & Fso & Pch & Pdi & & Rst & Ror & Tha & Tvi & \\
\hline 1 & S. Arjuni & \begin{tabular}{|l|}
50 \\
\end{tabular} & & 5 & 4 & & 3 & 7 & & 4 & 4 & & 4 & 2 & 5 & & 2 & 3 & 1 & & 2 & 4 \\
\hline 2 & Wadegaon & 43 & & 4 & 3 & 2 & 4 & & 3 & & 1 & 3 & 3 & 2 & 3 & & & 3 & & 3 & 4 & 5 \\
\hline 3 & Kohmara & 38 & & 3 & 2 & & & 2 & & 4 & & 4 & 5 & 2 & & 3 & 3 & 2 & & 2 & 1 & 5 \\
\hline 4 & Sawangi & 32 & 1 & 3 & & 2 & 3 & 2 & & & & 2 & 3 & & 4 & 2 & 1 & 1 & 2 & & 3 & 3 \\
\hline 5 & Saundad & 37 & 3 & 6 & 3 & & 3 & 4 & 2 & & 3 & 1 & & 2 & 2 & & 2 & 3 & 1 & & & 2 \\
\hline 6 & Tidka & 30 & & 4 & & 2 & 1 & 3 & & 2 & & 3 & 3 & & 3 & 2 & & 2 & & & 3 & 2 \\
\hline \multirow{2}{*}{\multicolumn{3}{|c|}{\begin{tabular}{l|r} 
Total & 230 \\
\% Contribution
\end{tabular}}} & 4 & 25 & 12 & 6 & 14 & 18 & 5 & 10 & 8 & 13 & 18 & 8 & 17 & 7 & 8 & 14 & 4 & 5 & 13 & 21 \\
\hline & & & 1.7 & 10.8 & 5.2 & 2.6 & 6.08 & 7.8 & 2.1 & 4.3 & 3.4 & 5.6 & 7.8 & 3.4 & 7.3 & 3.04 & 3.4 & 6.08 & 1.7 & 2.1 & 5.6 & 9.1 \\
\hline
\end{tabular}

Table 2: Frequency of Mycoflora in different Agricultural Fields as on Potato Dextrose Agar Medium

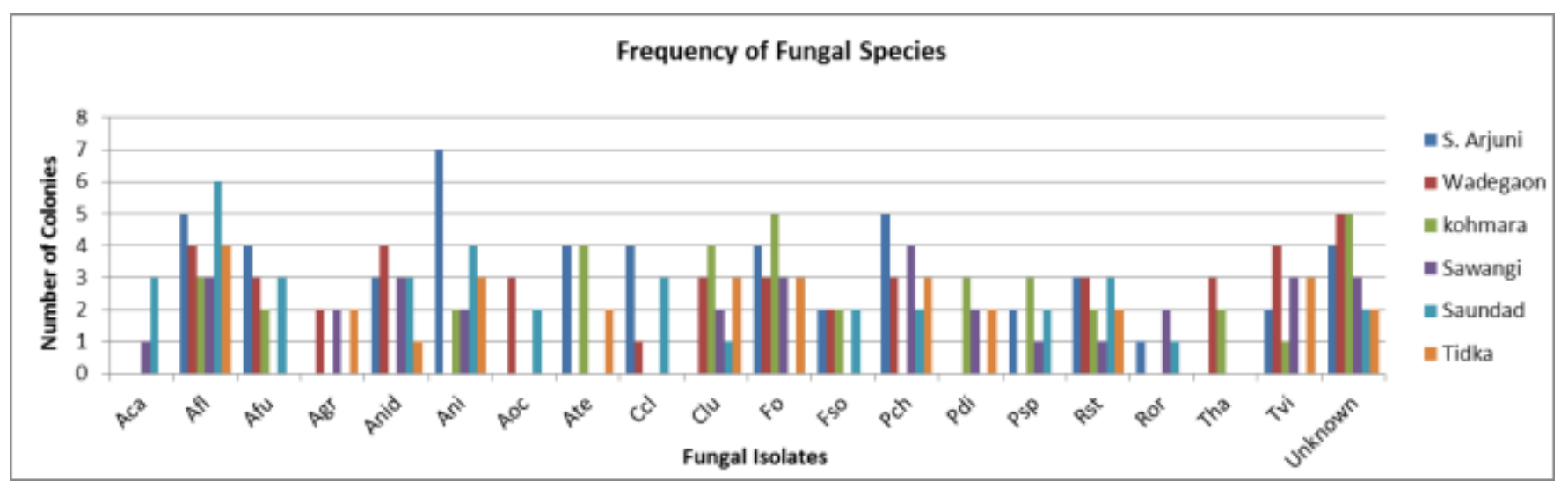

Graph 1: Frequency of Fungal species in different crop fields on PDA

Aca:-Aspergilluscandidus, Afl:-A. flavus, Afu:-A. fumigatus, Agr:-A. granulosus, Anid:-A. nidulans,Ani:-A. niger, Ate:-A. terreus, Afu:-Curvulariaclavata, Afu:-C. lunata, Afu:-C. lunata, Afu:-Fusarium oxysporium, Afu:-F. solani,Afu:PenicilliumChrysogenum, Pch:-P. chrysogenum,Pdi:-P. digitatum, Rst:-Rhizopusstolonifer, Ror:-R. oryzae, Tha:- 

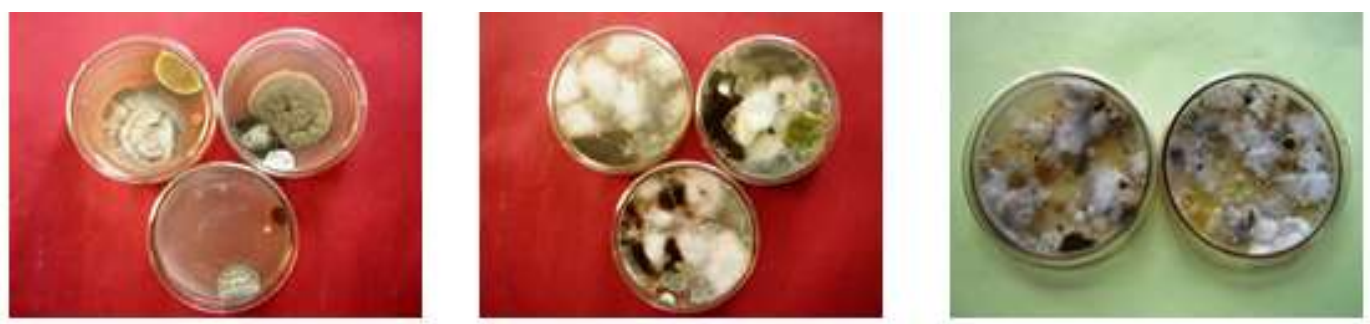

Fungi Isolated by Soil Dilution Method
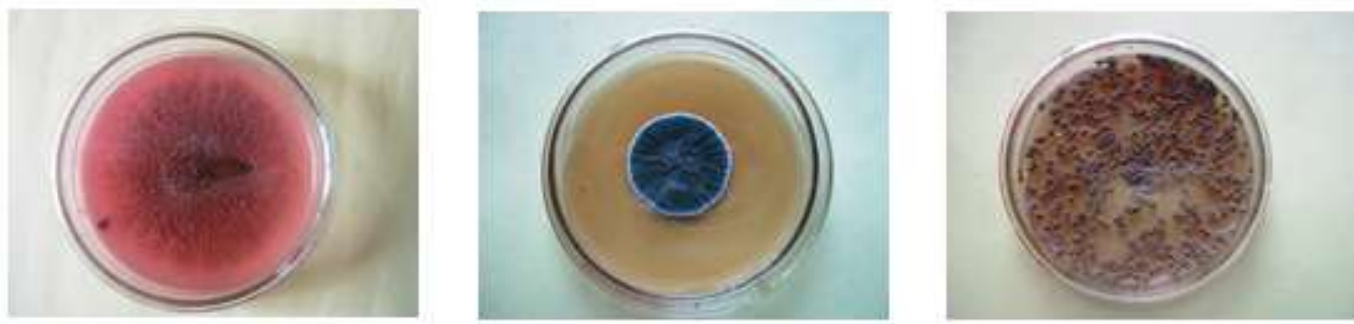

Pure Culture of Some Fungal species
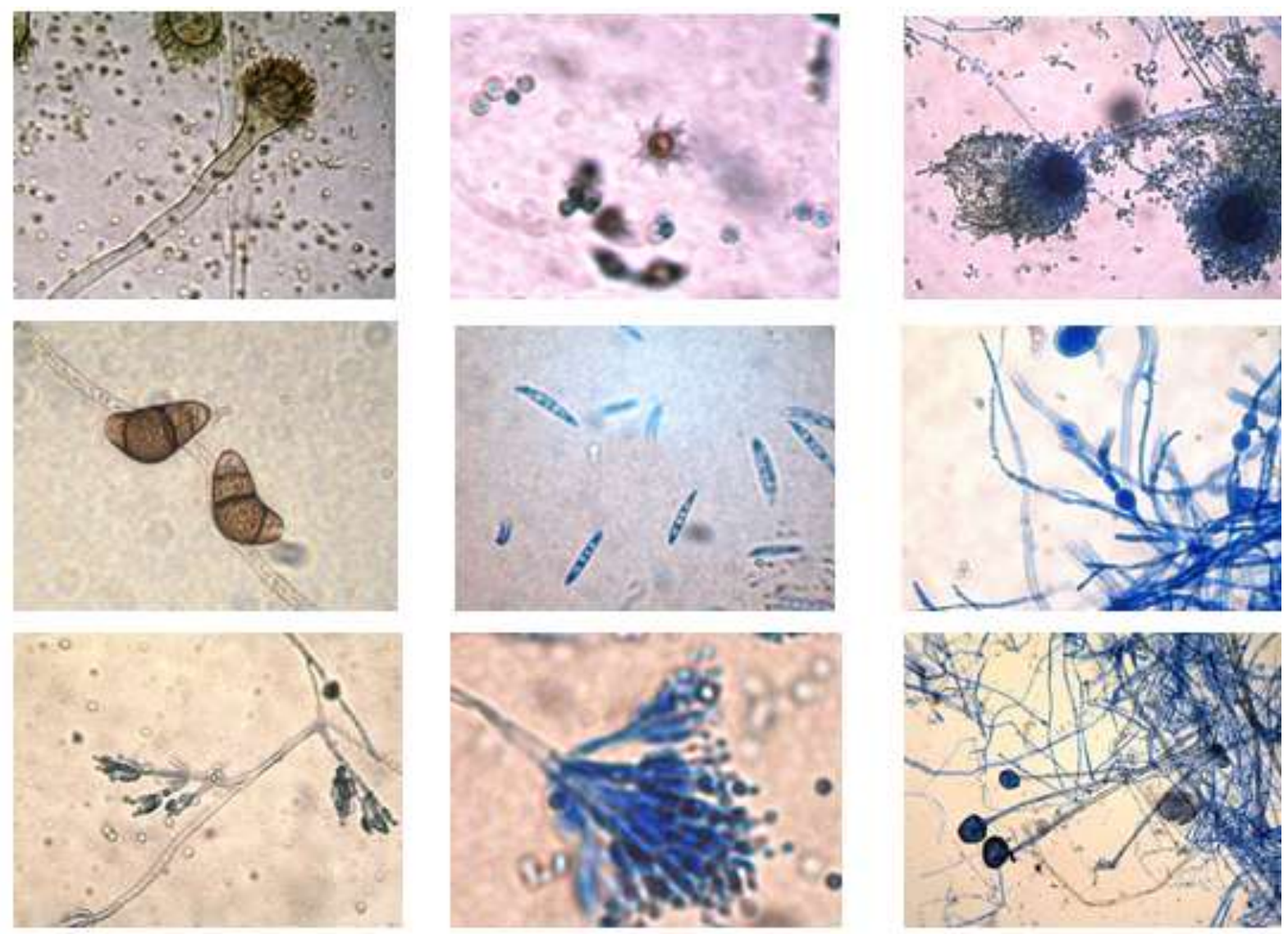

Fig.4: Some of the isolated fungal species 